\title{
Use of Thiopurines in Inflammatory Bowel Disease: A Consensus Statement by the Korean Association for the Study of Intestinal Diseases (KASID)
}

\author{
Kang-Moon Lee ${ }^{1}$, You Sun Kim², Geom Seog Seo ${ }^{3}$, Tae Oh Kim ${ }^{4}$, Suk-Kyun Yang ${ }^{5}$; \\ IBD Study Group of the Korean Association for the Study of Intestinal Diseases \\ Department of Internal Medicine, St. Vincent's Hospital, College of Medicine, The Catholic University of Koreal, Suwon, Department of Internal \\ Medicine, Seoul Paik Hospital, Inje University College of Medicine², Seoul, Department of Internal Medicine, Digestive Disease Research \\ Institute, Wonkwang University College of Medicine ${ }^{3}$, Iksan, Department of Internal Medicine, Haeundae Paik Hospital, Inje University College \\ of Medicine, Busan, Department of Gastroenterology, Asan Medical Center, University of Ulsan College of Medicine, Seoul, Korea
}

Background/Aims: For decades, thiopurines have been the mainstay of inflammatory bowel disease (IBD) treatment and will play an important role in the future. However, complex metabolism and various side effects limit the use of these potent drugs in clinical practice. The Korean Association for the Study of Intestinal Diseases developed a set of consensus statements with the aim of guiding clinicians on the appropriate use of thiopurines in the management of IBD. Methods: Sixteen statements were initially drafted by five committee members. The quality of evidence and classification of recommendation were assessed according to the Grading of Recommendations Assessment, Development and Evaluation system. The statements were then circulated to IBD experts in Korea for review, feedback, and then finalized and accepted by voting at the consensus meeting. Results: The consensus statements comprised four parts: (1) pre-treatment evaluation and management strategy, including value of thiopurine S-methyltransferase screening, dosing schedule, and novel biomarkers for predicting thiopurine-induced leukopenia; (2) treatment with thiopurines with regards to optimal duration of thiopurine treatment and long-term outcomes of combination therapy with anti-tumor necrosis factors; (3) safety of thiopurines, especially during pregnancy and lactation; and (4) monitoring side effects or efficacy of therapy using biomarkers. Conclusions: Thiopurines are an effective treatment option for patients with IBD. Management decisions should be individualized according to the risk of relapse and adverse events. (Intest Res 2015;13:193-207)

Key Words: Thiopurines, Inflammatory bowel disease, Consensus statement

\section{INTRODUCTION}

Since the 1980s, thiopurine agents such as azathioprine (AZA) and 6-mercaptopurine (6-MP) have been widely

Received April 27, 2015. Revised April 29, 2015. Accepted May 6, 2015. Correspondence to Suk-Kyun Yang, Department of Gastroenterology, Asan Medical Center, University of Ulsan College of Medicine, 88 Olympic-ro 43gil, Songpa-gu, Seoul 138-736, Korea. Tel: +82-2-3010-3901, Fax: +82-2476-0824,E-mail:sky@amc.seoul.kr

Financial support: This study was supported by a grant of the Korean Health Technology R\&D Project, Ministry of Health $\&$ Welfare, Republic of Korea (A120176). Conflict of interest: None. used for the treatment of IBD. It has been reported that thiopurines are effective at maintaining remission in steroid-dependent or steroid-refractory CD and UC and have steroidsparing effect. ${ }^{1-3}$ They have also shown efficacy in preventing postoperative recurrence of $\mathrm{CD} .^{4,5}$ Although their clinical implications are limited, thiopurines remain a mainstay of treatment of patients with IBD in the biologic era. However, possible toxicities such as bone marrow suppression, hepatotoxicity, and increased risk of opportunistic infections and malignancies interfere with the use of these potent drugs in clinical practice.

\footnotetext{
(c) Copyright 2015. Korean Association for the Study of Intestinal Diseases. All rights reserved.

This is an Open Access article distributed under the terms of the Creative Commons Attribution Non-Commercial License (http://creativecommons.org/licenses/by-nc/4.0) 
At present, there exist several questions regarding the optimization of thiopurine therapy. To balance the efficacy with safety and tolerability, thiopurine S-methyltransferase (TPMT) pretreatment screening, prudent dose escalation, and careful monitoring using novel biomarkers have been suggested ${ }^{6-8}$ However, most of the current guidelines for thiopurine use in IBD have been established based on western data. It has been widely accepted that notable differences in the context of epidemiology, genetics, and clinical characteristics exist between Western countries and East Asia, including Korea. ${ }^{9,10}$ Therefore, there is a definite need to establish management strategies that are more suitable for Korean patients.

For this reason, the Korean Association for the Study of Intestinal Diseases (KASID) developed a set of consensus statements on thiopurine use in IBD. The aim of these statements is to offer guidance to clinicians on the appropriate use of thiopurines in the management of IBD.

\section{METHODS}

The committee for the development of consensus statements comprised five members of KASID (working group). The committee conducted extensive literature review regarding thiopurine use in IBD and developed initial statements. Sixteen consensus statements were drafted after several revisions. The statements consisted of four parts: (1) pre-treatment evaluation and management strategy, (2) treatment with thiopurines, (3) safety of thiopurines, and (4) monitoring of side effects or efficacy of therapy.

The quality of evidence and classification of recommenda- tion was assessed according to the Grading of Recommendation Assessment, Development and Evaluation (GRADE) system. ${ }^{11}$ In this system, the quality of evidence of each statement was categorized as high, moderate, low, or very low. Evidence based on randomized controlled trials was initially classified as high-quality evidence, but the rating could be downgraded for several reasons including study limitations, inconsistency of results, indirectness of evidence, imprecision, and reporting bias. Although data from observational studies (e.g., cohort and case-control studies) were initially classified as low-quality evidence, the rating could be upgraded if the magnitude of the treatment effect is very large, if there is evidence of a dose-response relation, or if all plausible biases were found to decrease the magnitude of an apparent treatment effect. ${ }^{11,12}$ Based on the GRADE system, the strength of recommendations was classified as strong or weak, determined by four key factors including the balance between the desirable and undesirable effects, quality of evidence, values and preferences, and costs (resource allocation).$^{13}$ The definitions of the levels of evidence and recommendations are summarized in Table 1.

Prior to the consensus meeting, consensus statements were circulated to academic gastroenterologists with experience in managing patients with IBD and were revised in accordance with their comments and opinions regarding each statement.

The consensus meeting was held on April 18, 2015 in Seoul, Korea, wherein 38 IBD experts participated. During the meeting, the working group presented statements and all participants voted on their level of agreement regarding each statement. A consensus statement was accepted if at

Table 1. Definition(s) or Implication(s) of the Levels of Evidence and Recommendations ${ }^{11-13}$

\begin{tabular}{|c|c|}
\hline Level & Definition/implications \\
\hline High & We are very confident that the true effect lies close to that of the estimate of the effect. \\
\hline Low & $\begin{array}{l}\text { Our confidence in the effect estimate is limited: The true effect may be substantially different from } \\
\text { the estimate of the effect. }\end{array}$ \\
\hline Very low & $\begin{array}{l}\text { We have very little confidence in the effect estimate: The true effect is most likely to be substantially different } \\
\text { from the estimate of the effect. }\end{array}$ \\
\hline \multicolumn{2}{|c|}{ Classification of recommendations } \\
\hline Strong & Most patients should receive the recommended course of action. \\
\hline Weak & $\begin{array}{l}\text { Clinicians should recognize that different choices would be appropriate for different patients and that } \\
\text { they must help patients to arrive at a management decision consistent with her or his values and preferences. }\end{array}$ \\
\hline
\end{tabular}


least $75 \%$ of participants voted 1 (strongly agree) or 2 (agree) on a scale of 1 to 5 (with 3, 4, and 5 indicating uncertain, disagree, and strongly disagree, respectively). If a statement was not accepted, the wording of the statement was discussed and revised, and then re-voting was conducted.

\section{PRE-TREATMENT EVALUATION AND MANAGEMENT STRATEGY}

Statement 1.
Thiopurine-Induced Leukopenia Is More Common in
East Asians, Namely, Chinese, Japanese, and Koreans,
Compared to Caucasians.
Quality of evidence: Moderate
Classification of recommendation: Strong
Level of agreement: Strongly agree 55\%, Agree 40\%,
Uncertain 5\%

Thiopurines have been widely used for the treatment of patients with IBD. Recommended dosages for the treatment of IBD are $2.0-2.5 \mathrm{mg} / \mathrm{kg} / \mathrm{day}$ for AZA and $1.0-1.5 \mathrm{mg} / \mathrm{kg} /$ day for 6-MP ${ }^{6,7}$ However, one of the major drawbacks of the use of thiopurines is the development of leukopenia (defined as white blood cell [WBC] count $<3,000 / \mathrm{mm}^{3}$ ), occurring in up to $5 \%$ of Caucasian patients with IBD treated with these agents. ${ }^{14-16}$ Interestingly, the occurrence of thiopurineinduced leukopenia is considerably high in Asians. ${ }^{17-22}$ In a study by Lee et al., ${ }^{17}$ thiopurine-induced leukopenia was observed in 116 (31.2\%) of 372 Korean patients with CD at a median AZA dose of $1.34 \mathrm{mg} / \mathrm{kg} /$ day. In a study by Yang et al., ${ }^{18}$ leukopenia was noted in 346 (35.4\%) of 978 Korean patients with CD at a median AZA dose of $1.70 \mathrm{mg} / \mathrm{kg} /$ day. In another Korean multicenter study, ${ }^{19}$ leukopenia developed in $110(39.6 \%)$ of 278 patients with IBD at a mean AZA dose of $1.80 \mathrm{mg} / \mathrm{kg} /$ day. In two Japanese IBD cohorts with wildtype TPMT ${ }^{20,21}$ leukopenia was observed in $18(15.8 \%)$ of 114 patients and $7(10.0 \%)$ of 70 patients, although the total daily dose of AZA was only $50 \mathrm{mg}$ in the majority of patients. In a study by Fangbin et al., ${ }^{22}$ leukopenia $\left(\mathrm{WBC}<3,500 / \mathrm{mm}^{3}\right.$ ) was noted in 36 (18.1\%) of 199 Chinese patients with IBD. Since all these East-Asian studies used doses lower than the recommended dosage of AZA, more frequent and severe leukopenia is expected with standard doses of thiopurines in this population.

\section{Statement 2. \\ Assessment of the TPMT Genotype or Enzyme Activ- ity Before Initiating Thiopurine Therapy Is of Limited Value in East-Asian Populations Compared to That in Caucasians. \\ Quality of evidence: Moderate \\ Classification of recommendation: Weak \\ Level of agreement: Strongly agree $29 \%$, Agree $55 \%$, Uncertain $16 \%$}

AZA and 6-MP are metabolized by TPMT. TPMT mutations that result in decreased enzymatic activity are associated with a greater risk of thiopurine-induced leukopenia. ${ }^{23-26}$ Therefore, in order to mitigate the risk of leukopenia with thiopurines, the US Food and Drug Administration recommends an assessment of TPMT status prior to initiating therapy. ${ }^{7}$ However, only about a quarter of IBD patients with thiopurine-induced leukopenia carry a TPMT mutation, thus raising questions on the utility of TPMT pre-testing. ${ }^{27-29}$ Moreover, while the frequency of TPMT mutations is lower in Asians $(1-3 \%)^{18-22}$ than that in Caucasians $(\sim 10 \%),{ }^{30}$ the occurrence of thiopurine-induced leukopenia in Asians is considerably high, as described in the Statement $1 .{ }^{17-22}$ Consequently, TPMT mutations are present in only 0 to $5.6 \%$ of Asian patients with IBD who develop thiopurine-induced leukopenia. ${ }^{18-22}$ In addition, homozygotes for TPMT mutant alleles are extremely rare $(\sim 0.01 \%)$ in the Japanese population ${ }^{20}$ whereas their frequency is about $0.6 \%$ among Caucasians. ${ }^{31}$ Taken together, assessment of TPMT genotype/ phenotype prior to thiopurine therapy is of limited value in East-Asian populations, when compared with Caucasians.

\section{Statement 3.}

Gradual Increase in the Dosage of Thiopurines Over Several Months Until the Target Dose Is Usually Preferable to Beginning the Medication at the Target Dose at the Onset, in East Asians.

Quality of evidence: Low

Classification of recommendation: Weak

Level of agreement: Strongly agree $58 \%$, Agree $42 \%$

The recommend target dose of AZA and 6-MP for IBD treatment is $2.0-2.5 \mathrm{mg} / \mathrm{kg} /$ day and $1-1.5 \mathrm{mg} / \mathrm{kg} /$ day, respectively, if the patients can tolerate the drugs. ${ }^{6,7}$ However, the best approach to attain the target dose has not been established yet. The traditional "dose escalating approach" is to initiate the therapy at $50 \mathrm{mg}$ daily, then increase the dose by 
25 mg every 1-2 weeks to a target dose along with monitoring for leukopenia and other potential adverse events. ${ }^{7}$ The main concern regarding this approach is under-dosing of patients with a suboptimal response rate. An alternate approach is to start immediately at the full standard dose based on TPMT activity. According to this approach, patients with normal TPMT activity receive the standard dose while the patients with intermediate TPMT activity receive $50 \%$ of the standard dose. However, patients with low TPMT activity ( $0.3 \%$ of general population) should not be treated with thiopurines. ${ }^{32}$ Interestingly, a questionnaire-based survey showed that $33 \%$ of US gastroenterologists initiated therapy at $50 \mathrm{mg}$ of AZA, while $28 \%$ administered a full dose of AZA at $2.5 \mathrm{mg} / \mathrm{kg} /$ day, in clinical practice. ${ }^{33}$

Interestingly, the usual approach to prescribing thiopurines in East Asia is to start at a low dose and to gradually increase the dose ${ }^{34-37}$ According to a survey on clinical practice patterns in the treatment of IBD in Korea, $80 \%$ of the responders initiated AZA at $50 \mathrm{mg} /$ day, $68 \%$ increased the dose by 25 $\mathrm{mg}$, and $56 \%$ increased the dose every 4 weeks. ${ }^{34}$ This gradual dose increment policy could be useful for reducing AZAinduced myelotoxicity. ${ }^{35}$ However, it may delay the time to clinical response. In China, a dose step-up strategy is typically carried out by gradually increasing the dose of AZA to the target dose under close monitoring of laboratory results and clinical response. ${ }^{36}$ In Japan, lower doses of AZA ( $50 \mathrm{mg}$ /day or $0.6-1.2 \mathrm{mg} / \mathrm{kg} /$ day) are employed for the treatment of patients with IBD. ${ }^{20,37}$ Unlike Western data, several studies have suggested that lower doses of AZA or 6-MP may be effective and safe for the treatment of patients with IBD in East Asia. ${ }^{17,36-38}$ However, these studies did not compare the efficacies of lower doses with those of standard doses; moreover, they did not analyze the 6-thioguanine nucleotide (6-TGN) levels. Nevertheless, considering higher incidences of myelotoxicity ${ }^{17-22}$ and limited value of the assessment of TPMT genotypes, ${ }^{19-22,27-29,39}$ the dose escalating approach starting with low doses can be an effective and safe strategy in East Asians. However, there is currently no consensus on the rapidity of dosage increments.

\section{Statement 4. \\ Determination of NUDT15 Genotypes Before Initiating Thiopurine Therapy May Identify Patients With a Predisposition to the Development of Thiopurine-Induced Early Leukopenia.}

Quality of evidence: Moderate

Classification of recommendation: Strong

Level of agreement: Strongly agree $13 \%$, Agree $76 \%$, Uncertain $11 \%$
As described in Statement 2, assessment of the TPMT genotype or enzyme activity may play a limited role in the prevention of thiopurine-induced leukopenia in East Asians. Recently, a non-synonymous single nucleotide polymorphism in NUDT15 variant was identified as a significant risk factor for thiopurine-induced early leukopenia in Korean patients with CD. ${ }^{18}$ The NUDT15 allele encoding p.Arg139Cys was found in $89.4 \%$ of the early leukopenia cases but was found in only $6.8 \%$ of the controls, suggesting that the presence of the NUDT15 allele had a sensitivity of $89.4 \%$ and specificity of $93.2 \%$ to early leucopenia. Although rare, this single nucleotide polymorphism was also associated with thiopurine-induced leukopenia in Caucasians. ${ }^{18}$ The frequency of NUDT15 risk allele is much higher in East Asians than that in Caucasians (10.4\% in Koreans, $7 \%$ in Japanese, $13 \%$ in Chinese, and 2\% in an admixed American population). ${ }^{18}$ The results of this study were reproduced by a study in children with acute lymphoblastic leukemia conducted in the United States. ${ }^{39}$ Therefore, pre-treatment determination of NUDT15 genotypes may help to identify patients susceptible to thiopurine-induced early leukopenia in diverse populations, especially in East Asians.

\section{TREATMENT}

\section{Statement 5. \\ There Is Not Enough Evidence to Recommend Thiopurine Monotherapy for Induction of Remission in Active CD or UC. \\ Quality of evidence: Moderate \\ Classification of recommendation: Weak \\ Level of agreement: Strongly agree $42 \%$, Agree $53 \%$, Uncertain 5\%}

The data for thiopurines for remission induction in active UC is limited. ${ }^{40,41}$ In a meta-analysis of 4 randomized controlled trials $(n=89)$ evaluating the efficacy of AZA/6-MP for the induction of clinical remission of UC, the mean efficacy of AZA was not superior to placebo or 5-aminosalicylate (75\% vs. $64 \%$, respectively; OR, 1.59; 95\% CI, 0.59-4.29; $P=0.13) .^{41}$ Thiopurines may be effective for inducing remission in active CD as compared to placebo (OR, 2.43; 95\% CI, 1.62-3.64).$^{42}$ However, a recent Cochrane meta-analysis including 11 randomized trials reported that thiopurines offered no significant advantage over placebo for induction of clinical remission in active CD (48\% vs. $37 \%$, respectively; RR, 1.23; 95\% CI, 0.97-1.55). ${ }^{43}$ Usually, thiopurines have been 
limited in the use of remission induction in active CD or UC because of the delay in the onset of their action. ${ }^{44}$ Thiopurines may take 3-6 months to achieve full clinical efficacy. ${ }^{45}$ Therefore, in patients with active CD or UC requiring rapid symptom relief, concomitant therapy with systemic corticosteroids and thiopurines is a more reasonable approach. However, the addition of thiopurines to corticosteroids makes no benefit in terms of remission induction. ${ }^{44}$ Thiopurines have the benefit in corticosteroid sparing effect for active CD with a pooled OR of 3.69 (95\% CI, 2.12-6.42).

\section{Statement 6. \\ Thiopurines Are Effective for the Maintenance of Re- mission in Patients With CD and UC. \\ Quality of evidence: High \\ Classification of recommendation: Strong \\ Level of agreement: Strongly agree $66 \%$, Agree $32 \%$, Uncertain $2 \%$}

Thiopurines are effective for maintenance of remission in both UC and CD. ${ }^{2,3}$ AZA appears to be more effective than placebo for the maintenance of remission in UC. ${ }^{3}$ According to a meta-analysis of 4 studies including 232 patients with UC, $44 \%(51 / 115)$ of patients administered AZA failed to maintain remission compared to $65 \%(76 / 117)$ of placeboadministered patients (RR, 0.68 ; $95 \% \mathrm{CI}, 0.54-0.86$ ). ${ }^{3} \mathrm{AZA}$ or 6-MP may be effective as maintenance therapy in patients with UC who have failed to respond or cannot tolerate 5- aminosalicylate and in patients who require repeated courses of corticosteroids. In case of patients with CD, AZA or 6-MP also had a positive effect in maintaining remission. ${ }^{1,246,47}$ A meta-analysis of 8 studies including 503 patients with $\mathrm{CD}$ revealed that the overall remission rate was $71 \%$ (147/208; 95\% CI, 64-77\%) for AZA treatment compared to that for placebo (55\% [141/255]; 95\% CI, 49-61\%). ${ }^{2}$

AZA (1.0-2.5 mg/ $/ \mathrm{kg} /$ day) is effective in reducing the risk of disease recurrence over a 6-month to 2-year period. Higher doses of AZA $(2.5 \mathrm{mg} / \mathrm{kg} /$ day $)$ are more effective than the lower doses ( 1.0 or $2.0 \mathrm{mg} / \mathrm{kg} /$ day) in preventing disease recurrence. In addition, AZA has corticosteroid-sparing effects that reduce corticosteroid-related side effects. Previously, a Korean study also reported that complete withdrawal of corticosteroids was achieved in $70.9 \%$ of patients with CD receiving treatment with AZA. ${ }^{17}$ AZA or 6-MP may also benefit patients dependent on corticosteroids or in cases where corticosteroid treatment has failed. Among Korean patients with steroid-dependent UC, the 3-year success rate was higher in the AZA therapy group (71.2\%) than that in the AZA intolerance group $(25.0 \%) .^{38}$ However, withdrawals due to adverse events were more commonly observed in patients treated with AZA (Peto OR, 3.74; 95\% CI, 1.48-9.45) compared to placebo. ${ }^{2}$

Statement 7.
Optimal Duration of Treatment With Thiopurines Is
Uncertain. Prolonged or Indefinite Use of Thiopurines
May Be Considered to Maintain Remission. The Risk
and Benefits of Continuing Thiopurine Therapy Should
Be Balanced and Discussed With Individual Patients.
Quality of evidence: Low
Classification of recommendation: Weak
Level of agreement: Strongly agree $68 \%$, Agree $29 \%$,
Uncertain $3 \%$

Conclusive evidence suggests that thiopurines are effective for maintenance of remission in both CD and UC. ${ }^{2,3}$ Well-tolerated and effective therapy is generally continued to maintain the remission of IBD. However, the optimal duration of thiopurine use has not yet been determined. There is limited data regarding the factors predicting responses to AZA and the uncertainty regarding the optimal duration of treatment. ${ }^{48}$ In patients with CD, several studies showed relapse rates of $14-41 \%$ at 1 year after cessation of thiopurines with a cumulative increase with time. ${ }^{49-51}$ Furthermore, patients with CD who discontinued AZA after more than 3 years of efficacious treatment had a higher probability of relapse than those who continued therapy ${ }^{52}$ A recent metaanalysis showed that there is a clear benefit of continuing AZA/6-MP therapy for at least 18 months to maintain remission in patients with $\mathrm{CD}^{53}$ In patients with UC, relapse rates after cessation of AZA treatment were reported to be 35-77\% and $65-75 \%$ at 1 and 5 years, respectively. ${ }^{16,54,55}$ There was no difference in the relapse rates between $\mathrm{CD}$ and UC. The duration of AZA treatment did not affect the relapse rates after cessation of treatment $(P=0.68) .{ }^{16}$ According to the European Crohn's and Colitis Organisation (ECCO) guidelines, ${ }^{56}$ for patients with $\mathrm{CD}$ who have been treated with thiopurines as part of maintenance therapy, discontinuation may be considered after 4 years of remission.

To summarize these data, thiopurines should be used for at least 18 months after achieving remission and could be continued for over 4 years. Therefore, considering the high cumulative relapse rates after cessation of thiopurine treatment, risk stratification is an important issue for pa- 
tients with IBD receiving thiopurines. Meanwhile, frequent adverse events sometimes led to discontinuation of the thiopurine agents. Most frequent adverse events were nausea, hepatotoxicity, myelotoxicity, and pancreatitis. Overall, around $10-28 \%$ of patients reported side effects and of which $50-80 \%$ discontinued the thiopurines as a result. ${ }^{57}$ In addition to risk factors for disease relapse, adverse events with long-term use such as serious infections and malignancies must be taken into account. Thus, benefits and risks of continuing thiopurines should be considered and discussed with each patient individually.

\begin{tabular}{l} 
Statement 8. \\
The Combination of Anti-Tumor Necrosis Factor (TNF)- $\alpha$ \\
Agents and Thiopurines Is More Effective Than That of \\
Monotherapy With Anti-TNF- $\alpha$ Agents* or Thiopurines \\
Alone in Inducing Remission in Patients With Moderate \\
to Severe CD. \\
*Anti-TNF- $\alpha$ Agents \\
Quality of evidence: Moderate \\
Classification of recommendation: Weak \\
Level of agreement: Strongly agree 26\%, Agree $58 \%$, \\
$\quad$ Uncertain $16 \%$ \\
Thiopurines \\
Quality of evidence: High \\
Classification of recommendation: Strong \\
Level of agreement: Strongly agree $70 \%$, Agree $24 \%$, \\
$\quad$ Uncertain $6 \%$ \\
\hline
\end{tabular}

Several studies have reported the effectiveness of combination of anti-TNF agents with thiopurines in case of rheumatic diseases and IBD. Thiopurines improved the pharmacokinetics of anti-TNF agents and decreased the formation of anti-drug antibodies. ${ }^{58}$ In the SONIC (The study of Biologic and Immunomodulator Naive Patients in Crohn's disease) trial that included immunosuppressant-naive CD patients, the corticosteroid-free remission rates and mucosal healing rates were higher in those treated with a combination of infliximab plus AZA than those treated with infliximab or AZA alone. ${ }^{59}$ The corticosteroid-free remission rates at week 26 were $57 \%$ in those receiving combination therapy, $44 \%$ in those receiving infliximab alone, and $30 \%$ in patients receiving AZA alone. At week 50, the corticosteroid-free remission rates were $72 \%, 61 \%$, and $55 \%$. Additionally, mucosal healing rates were evaluated at week 26 and they were $44 \%, 30 \%$, and $16.5 \%$, respectively. ${ }^{59}$ In the GETAID (Groupe d'Etude Therap-utique des Affections Inflammatoires du tube Diges- tif) study, infliximab plus AZA/6-MP was found to be more effective than AZA/6-MP alone for the induction of remission in patients with corticosteroid-dependent $\mathrm{CD}^{60}$

In case of adalimumab, a recent meta-analysis study demonstrated that adalimumab monotherapy was inferior when compared to combination therapy with adalimumab plus thiopurines (OR, $0.78 ; P=0.02)$ for induction of remission in patients with $\mathrm{CD}$. However, the rate of remission at 1 year and the need for dose escalation was similar in both groups. ${ }^{61}$ Therefore in patients with moderate to severe $\mathrm{CD}$, especially in case of immunosuppressant-naive patients with CD, a combination therapy with anti-TNF and thiopurines seems to be preferred mode of treatment in order to allow the patients to achieve the highest rate of rapid disease control and limited tissue damage. However, the benefit of combination therapy in immunosuppressant treatmentfailed patients remains unclear.

Statement 9.
The Combination of Anti-TNF- $\alpha$ Agents and Thiopu-
rines Is More Effective Than That of Monotherapy With
Anti-TNF- $\alpha$ Agents* or Thiopurines ${ }^{\dagger}$ Alone in Inducing
Remission in Patients With Moderate to Severe UC.
*Anti-TNF- $\alpha$ Agents
Quality of evidence: Moderate
Classification of recommendation: Weak
Level of agreement: Strongly agree $18 \%$, Agree $66 \%$,
$\quad$ Uncertain $16 \%$
'Thiopurines
Quality of evidence: High
Classification of recommendation: Strong
Level of agreement: Strongly agree $55 \%$, Agree $42 \%$,
Disagree $3 \%$

The main question that remains to be answered in this clinical situation is whether combination therapy with infliximab and thiopurines is clearly superior to monotherapy with infliximab or thiopurines alone, in patients with UC. Recently, the UC SUCCESS (Efficacy and Safety of Infliximab and Azathioprine Monotherapy or in Combination in Moderate to Severe UC) trial was performed to provide a suitable explanation for the above question. ${ }^{62}$ This study was a randomized, double-blind clinical trial for evaluating the efficacy and safety of 16 weeks of infliximab plus AZA, infliximab or AZA monotherapy in patients with moderate to severe UC. ${ }^{62}$ At week 16, a greater proportion of patients 
in the infliximab plus AZA achieved corticosteroid-free remission (39.7\%) compared to $22.1 \%$ receiving infliximab alone $(P=0.017)$ and $23.7 \%$ receiving AZA alone $(P=0.032)$. Mucosal healing at week 16 occurred in $62.8 \%$ of patients receiving infliximab plus AZA, compared to $54.6 \%$ receiving infliximab alone $(P=0.295)$ and $36.8 \%$ receiving AZA alone $(P=0.001)$. Adverse events that required discontinuation of therapy were higher in the AZA alone (8\%) than in the infliximab alone (3\%) or the infliximab plus AZA group (4\%). Although there are no high quality reports regarding the superiority of combination therapy except for the UC SUCCESS trial, infliximab-based combination therapy can be more therapeutically useful in patients with moderate to severe UC who previously do not appear to respond adequately to corticosteroid therapy. The combination of adalimumab and immunomodulator appeared mildly superior to adalimumab monotherapy for the induction of remission in $\mathrm{CD}^{61}$ However, it is still unclear in case of UC.

\section{Statement 10. \\ Selection Between Anti-TNF- $\alpha$ Monotherapy and Combination Therapy With an Immunomodulator May Be Individualized Based on the Risk of Relapse and Adverse Events. Currently, No Recommendation Can Be Given for the Duration of Combination Thera- py. \\ Quality of evidence: Low \\ Classification of recommendation: No \\ Level of agreement: Strongly agree $32 \%$, Agree $65 \%$, Uncertain 3\%}

As described in Statements 8 and 9, combination therapy with infliximab and thiopurines is more effective than monotherapy with either agent alone in inducing corticosteroidfree clinical remission and mucosal healing in patients with CD and UC who are naive to either agent. ${ }^{59,62}$ Meanwhile, the clinical benefits of continuing immunomodulators in patients with IBD who are refractory to these drugs when starting anti-TNF therapy are debatable. However, combination therapy with anti-TNF agents and immunomodulators may increase the risk of serious infections and malignancies. In a study with longitudinal cohort of 8,581 CD patients, ${ }^{63}$ monotherapy with steroids, immunomodulators, or anti-TNF agents was associated with an increased risk of tuberculosis, candidiasis, herpes zoster, and sepsis as compared to patients not receiving these medications. The combination of two or three medications further increased the risk of these infections. In contrast, according to the TREAT (Crohn's Therapy, Resource, Evaluation and Assessment Tool) registry ${ }^{64} \mathrm{CD}$ severity and use of prednisone or narcotic analgesics showed higher risks of serious infection, although an increased risk was also observed with infliximab. Moreover, treatment with immunomodulators including thiopurines and methotrexate was not a significant predictor of serious infection, and combination therapy with infliximab and immunomodulators did not increase the risk of infection, compared with infliximab monotherapy. Therefore, relationship between combination therapy with infliximab and immunomodulators and development of serious infections remains unclear. The risk of neoplasm in IBD patients receiving antiTNF therapy is controversial. ${ }^{65,66}$ The combination of antiTNF agents and immunomodulators is associated with an increased risk of malignancies such as lymphoma and nonmelanoma skin cancer. ${ }^{67-69}$ The risks of these cancers are largely driven by the use of concomitant immunomodulators, particularly thiopurines. ${ }^{70}$

In order to decide between the combination therapy versus monotherapy approach, we should weigh the increased risk of complications induced by combination therapy against the increased risk of relapse observed with monotherapy. According to a decision analytic model, the benefits of combination therapy with infliximab and AZA would outweigh the risks in CD patients who are naive to either agent, unless serious infections occurred in $20 \%$ or more of the population or lymphoma in $3.9 \%$ or more. ${ }^{71}$ Old age $(>65$ years) is associated with a greater risk of serious infections and lymphoproliferative disorder. ${ }^{72,73}$ Hepatosplenic T-cell lymphoma usually occurs in young men $(<35$ years) receiving thiopurine therapy for more than 2 years. ${ }^{74}$ Factors associated with the risk of relapse after cessation of concomitant immunomodulators include increased inflammatory markers, evidence of mucosal activity on endoscopy, short duration in remission before stopping therapy, and undetectable trough levels of anti-TNF. ${ }^{70}$ Therefore, withdrawal of concomitant immunomodulators may be considered in patients in deep remission for a considerable period and with detectable anti-TNF trough levels, especially in elderly patients or young male patients. Currently, there is no consensus on the duration of combination therapy with an anti-TNF agent and an immunomodulator. 


\section{SAFETY}

Statement 11.
Use of Thiopurines Is Associated With an Increased
Risk of Lymphoma and Non-Melanoma Skin Cancers.
However, the Absolute Risks of These Malignancies
Remain Low. These Risks Should Be Weighed Against
the Substantial Benefits of Thiopurine Therapy.
Quality of evidence: Moderate
Classification of recommendation: Strong
Level of agreement: Strongly agree 51\%, Agree $49 \%$

According to a recent meta-analysis by Kotlyar et al., ${ }^{75}$ the overall standardized incidence ratio (SIR) for lymphoma was 4.92 (95\% CI, 3.10-7.78) in patients with IBD exposed to thiopurines: $2.80(95 \% \mathrm{CI}, 1.82-4.32)$ in 8 population studies and 9.24 (95\% CI, 4.69-18.2) in 10 referral studies. In 8 population studies, an increased risk was noted among current users (SIR, 5.71; 95\% CI, 3.72-10.1) but not among former users (SIR, 1.42; 95\% CI, 0.86-2.34). ${ }^{75}$ Young male patients ( $<30$ years) had the highest SIR, and aged patients (>50 years) showed the highest absolute risk. ${ }^{75}$ According to a recent meta-analysis involving 60,351 IBD patients, the pooled adjusted hazards ratio of developing non-melanoma skin cancers after exposure to thiopurines was 2.28 (95\% CI, 1.50-3.45) ${ }^{76}$ However, the results of this meta-analysis must be interpreted carefully owing to a marked heterogeneity between studies. There is not enough evidence to suggest that the modestly increased risk of lymphoma and non-melanoma skin cancers outweighs the benefit of thiopurines in IBD. $^{67,76}$

\section{Statement 12. \\ Use of Thiopurines Is Not Associated With an Increased Risk of Postoperative Complications. \\ Quality of evidence: Low \\ Classification of recommendation: Weak \\ Level of agreement: Strongly agree 30\%, Agree 67\%, Uncertain $3 \%$}

Postoperative complications in IBD include abdominal sepsis, wound problem, anastomotic leakage, early reoperation as well as complicated systemic diseases leading to increased morbidity and mortality. In case of CD, a study by Colombel et al. ${ }^{77}$ reported that early postoperative complications did not increase in patients with CD treated periopera- tively with immunosuppressive agents. However, in a study by Myrelid et al., ${ }^{78}$ preoperative thiopurine therapy was associated with postoperative intra-abdominal septic complications in case of abdominal surgery for patients with CD. As for UC, in a study by Schaufler et al., ${ }^{79}$ preoperative exposure to thiopurines was not associated with increased postoperative complications in a cohort undergoing colectomy for UC or IBD-U. Recently, a meta-analysis involving 21 studies with 6,899 IBD patients evaluated whether the preoperative use of immunosuppressive agents was associated with increased postoperative complications in patients with IBD. ${ }^{80}$ Of these 21 studies, 8 studies with 1,674 patients reported the impact of preoperative thiopurines on postoperative outcomes. The pooled risk ratio estimates for total complications and infectious postoperative complications were 0.97 (95\% CI, 0.69-1.36) and 1.23 (95\% CI, 0.66-2.29), thus suggesting no association between preoperative use of thiopurines and postoperative complications. ${ }^{80}$ However, most studies were retrospectively designed and there were large variations in the patient populations and outcome definitions. ${ }^{80}$

\section{Statement 13. \\ Thiopurines Are Considered to Be Safe and Well Tol- erated During Pregnancy. Discontinuing Thiopurine Therapy During Pregnancy May Precipitate a Flare Resulting in Adverse Neonatal Outcomes. \\ Quality of evidence: Moderate \\ Classification of recommendation: Weak \\ Level of agreement: Strongly agree $16 \%$, Agree $71 \%$, Uncertain $13 \%$}

The peak incidence of IBD occurs in women of childbearing age. Management of patients with IBD during pregnancy requires a challenging balance between optimal disease control and drug safety considerations. Fears about the potential harm of IBD medications to the developing fetus are very common. In a survey conducted in Australia, $36.1 \%$ of participants believed that any form of IBD medication was harmful to the unborn fetus. ${ }^{81}$ However, discontinuation of therapy may result in disease relapse during pregnancy, which carries a greater risk of adverse fetal outcomes (a higher rate of fetal loss, preterm birth, and low birth weight), according to a number of reports. ${ }^{82-87}$

Conflicting data exist regarding the association between thiopurine use for IBD treatment in pregnancy and adverse pregnancy outcomes. A few studies reported an increased risk of fetal loss, preterm delivery, low birth weight, and con- 
genital abnormalities when thiopurines were used during pregnancy. ${ }^{88-90}$ However, these outcomes might have been caused by the underlying disease rather than thiopurines. A majority of recently conducted controlled or cohort studies have not shown an increase in congenital abnormalities. ${ }^{91-95}$ According to a recent pharmacological study conducted on thiopurines in pregnant patients with IBD, although unborn children were exposed in utero to the pharmacologically active thiopurine metabolites 6-TGN, no major teratogenicity was observed.$^{96}$ In another study, thiopurine use during pregnancy did not affect long-term development or immune function of children up to 6 years of age ${ }^{97}$ Moreover, two recent meta-analyses did not demonstrate an increased risk of fetal loss, low birth weight, or congenital abnormalities despite intrauterine exposure to thiopurines. ${ }^{98,99}$ However, an association with preterm birth was noted in one out of the two meta-analyses studies. ${ }^{98}$ In addition, $60 \%$ of newborns exposed to thiopurines in utero were anemic at birth. ${ }^{96}$

Existing guidelines suggest that thiopurines should not be discontinued during pregnancy. ${ }^{100-103}$ In a worldwide survey among 175 IBD experts, 155 (89\%) physicians replied that they would continue AZA therapy throughout pregnancy. ${ }^{4}$ The potential risks and benefits of thiopurine therapy should be discussed with a patient, ideally prior to conception.

Statement 14.
Breastfeeding Could Be Advised for Women on
Thiopurine Maintenance Therapy Willing to Nurse
Their Infants. The Risks and Benefits of Thiopurine
Therapy Should Be Discussed With the Mother.
Quality of evidence: Moderate
Classification of recommendation: Weak
Level of agreement: Strongly agree $23 \%$, Agree $64 \%$,
Uncertain $13 \%$

Treatment with thiopurines is widely used to maintain remission in IBD. Female patients with IBD may require treatment with thiopurines during lactation to maintain remission. Breastfeeding by patients with IBD patients on thiopurines is probably safe because the presence of only trace amounts of AZA/6-MP metabolites has been noted in breast milk.

In a prospective study, the concentration of 6-MP was measured in 31 breast milk samples collected from 10 mothers receiving AZA. ${ }^{104} 6$-MP was detected in low concentrations ( 1.2 and $7.6 \mathrm{ng} / \mathrm{mL}$, as compared to therapeutic immunomodulator level of $50 \mathrm{ng} / \mathrm{mL}$ in serum) in two samples, but was not detected in any of the other 29 samples. ${ }^{104} \mathrm{Ad}-$ ditionally, AZA/6-MP metabolites were undetectable in the neonatal blood. ${ }^{97,104}$ The majority of thiopurine metabolites are excreted in milk in the first 4 hours after intake of the drug. ${ }^{105}$ Hence, mothers should be counseled to use a breast pump 4 hours after medication intake to discard the first portion of milk produced after AZA intake in order to minimize the infant's exposure to the drug.

Breastfeeding by IBD patients undergoing thiopurine therapy did not affect long-term development or immune function. One retrospective study showed no differences in infection rate in children breastfed by mothers receiving thiopurines for IBD as compared to children breastfed by mothers without immunomodulator therapy. ${ }^{92}$ Another recent observational study showed no differences in any of the global medical and psychosocial health status in 9 breastfed infants (for median 7 months, range 3-13 months) and the formula-fed group. ${ }^{106}$ Thiopurines can be administered safely to women with IBD during lactation. Therefore, breastfeeding should be recommended after considering its beneficial therapeutic effects for the nursing mother with IBD. Appropriate counseling for lactation should be available for all lactating women with IBD in order to discuss the risks and benefits of thiopurine therapy.

\section{MONITORING}

\section{Statement 15. \\ Close Follow-Up of Full Blood Counts Is Recommended in All Patients Taking Thiopurines. However, the Optimal Frequency of Measurement Has Not Been Evaluated Systematically. \\ Quality of evidence: Moderate \\ Classification of recommendation: Weak \\ Level of agreement: Strongly agree $28 \%$, Agree $67 \%$, Uncertain 5\%}

Thiopurines have been reported to increase the risk of myelotoxicity, particularly leukopenia. Myelotoxicity is one of the more common dose-dependent adverse effects with potentially serious clinical consequences. The use of complete blood counts (CBC) to monitor bone marrow suppression is of particular importance. ${ }^{107}$ Most cases of severe leukopenia occur abruptly early on in treatment. ${ }^{107}$ In a study by Lewis et al., the incidence of severe leukopenia $\left(\mathrm{WBC}<1,000 / \mathrm{mm}^{3}\right.$ ) was highest in the first 8 weeks of thiopurine therapy with the median time from onset of therapy to first documenta- 
tion of severe leukopenia being 24.5 days. ${ }^{108}$

There is currently no clear consensus on optimal frequency of blood monitoring. ${ }^{109}$ Several monitoring guidelines have been proposed. ${ }^{15,107,110,111}$ A Western study stated that a CBC should be obtained weekly for one month, biweekly for the second month, monthly for four months and, bimonthly when the patient is stable after six months of treatment. Although further studies are needed in order to better define the optimal interval of CBC monitoring, it may be scheduled biweekly for the first two months, and then every 4-12 weeks thereafter, in general.

\section{Statement 16. \\ The Dose Adjustment of Thiopurines Through Monitoring of 6-TGN and 6-Methylmercaptopurine (6-MMP) Levels Is Expected to Improve Efficacy and Reduce Side Effects in Patients Treated With Thiopu- rines. \\ Quality of evidence: Moderate \\ Classification of recommendation: Weak \\ Level of agreement: Strongly agree 18\%, Agree 69\%, Uncertain $13 \%$}

The variation between clinical efficacy and side-effect profile of thiopurines is may be attributed to individual differences in drug metabolism. 6-MP and its prodrug AZA are converted to 6-TGN, which is the main active metabolite responsible for therapeutic efficacy and myelotoxicity. On the other hand, metabolism of these products also yields 6-MMP, high levels of which are associated with increased hepatotoxicity.

These findings have led to strategies for advantageously shifting thiopurine metabolism toward optimal 6-TGN levels while decreasing 6-MMP levels in an attempt to benefit a greater portion of patients undergoing thiopurine treatment. Although the relationship between 6-TGN levels and efficacy was first described in patients with IBD in $1996,{ }^{109}$ this correlation was confirmed in the landmark study in 2000 by Dubinsky et al., ${ }^{112,113}$ which demonstrated a positive correlation of therapeutic response with 6-TGN levels in 92 pediatric patients with IBD. The frequency of therapeutic response increased at 6 -TGN levels $>235 \mathrm{pmol} / 8 \times 10^{8}$ red blood cells (RBC) while hepatotoxicity correlated with elevated 6-MMP

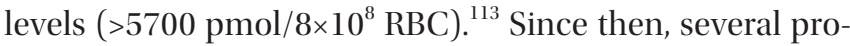
spective studies have reported a correlation between 6-TGN levels and clinical response. ${ }^{114-117}$ A meta-analysis of 12 studies with 941 patients concluded that patients with 6-TGN levels above $230-260 \mathrm{pmol} / 8 \times 10^{8} \mathrm{RBC}$ were more likely to be in remission than those below the threshold value. ${ }^{8} \mathrm{~A}$ more recent pooled analysis including 17 studies of 2,049 patients showed that the pooled OR for clinical remission among patients with 6-TGN levels over a cut-off value between 230 and $260 \mathrm{pmol} / 8 \times 10^{8} \mathrm{RBC}$ was $3.15 .{ }^{118}$ Although the dose adjustment of thiopurines through monitoring of 6-TGN and 6-MMP levels is expected to improve efficacy and reduce side effects in patients treated with thiopurines, further studies are needed in order to confirm these findings.

\section{CONCLUSIONS}

For decades, thiopurine agents have been a mainstay in treating IBD and will play an important role in the future. However, complex metabolism and various side effects limit their successful application in clinical practice. Thiopurineinduced leukopenia is especially very common and prescreening for TPMT has a limited value in Korean patients with IBD. Gradual dose increment with careful monitoring of $\mathrm{CBC}$ is essential to reduce this complication. Maintaining with low dose of thiopurines can be a great alternative. In addition, use of novel biomarkers such as NUDT15, may help identify patients who are at a high risk for thiopurine-induced leukopenia. At present, optimal duration of thiopurine treatment in addition to long-term outcomes of combination therapy with anti-TNF agents is uncertain. Management decisions should be individualized based on the risk of relapse and adverse events. Although thiopurine treatment during pregnancy and lactation is considered safe and well tolerated, it is important to balance the risks and benefits.

\section{REFERENCES}

1. Present DH, Korelitz BI, Wisch N, Glass JL, Sachar DB, Pasternack BS. Treatment of Crohn's disease with 6-mercaptopurine. A long-term, randomized, double-blind study. N Engl J Med 1980;302:981-987.

2. Prefontaine E, Sutherland LR, Macdonald JK, Cepoiu M. Azathioprine or 6-mercaptopurine for maintenance of remission in Crohn's disease. Cochrane Database Syst Rev doi: 10.1002/14651858.CD000067.pub2. Published online 21 January 2009.

3. Timmer A, McDonald JW, Tsoulis DJ, Macdonald JK. Azathioprine and 6-mercaptopurine for maintenance of remission in ulcerative colitis. Cochrane Database Syst Rev doi: 10.1002/14651858.CD000478.pub3. Published online 12 September 2012. 
4. Peyrin-Biroulet L, Deltenre P, Ardizzone S, et al. Azathioprine and 6-mercaptopurine for the prevention of postoperative recurrence in Crohn's disease: a meta-analysis. Am J Gastroenterol 2009;104:2089-2096.

5. Reinisch W, Angelberger S, Petritsch W, et al. Azathioprine versus mesalazine for prevention of postoperative clinical recurrence in patients with Crohn's disease with endoscopic recurrence: efficacy and safety results of a randomised, doubleblind, double-dummy, multicentre trial. Gut 2010;59:752-759.

6. Siegel CA, Sands BE. Review article: practical management of inflammatory bowel disease patients taking immunomodulators. Aliment Pharmacol Ther 2005;22:1-16.

7. Lichtenstein GR, Abreu MT, Cohen R, Tremaine W; American Gastroenterological Association. American Gastroenterological Association Institute technical review on corticosteroids, immunomodulators, and infliximab in inflammatory bowel disease. Gastroenterology 2006;130:940-987.

8. Osterman MT, Kundu R, Lichtenstein GR, Lewis JD. Association of 6-thioguanine nucleotide levels and inflammatory bowel disease activity: a meta-analysis. Gastroenterology 2006;130:1047-1053.

9. Ng SC, Tsoi KK, Kamm MA, et al. Genetics of inflammatory bowel disease in Asia: systematic review and meta-analysis. Inflamm Bowel Dis 2012;18:1164-1176.

10. Kim ES, Kim WH. Inflammatory bowel disease in Korea: epidemiological, genomic, clinical, and therapeutic characteristics. Gut Liver 2010;4:1-14.

11. Guyatt GH, Oxman AD, Vist GE, et al. GRADE: an emerging consensus on rating quality of evidence and strength of recommendations. BMJ 2008;336:924-926.

12. Balshem H, Helfand M, Schünemann HJ, et al. GRADE guidelines: 3. Rating the quality of evidence. J Clin Epidemiol 2011;64:401-406.

13. Guyatt GH, Oxman AD, Kunz R, et al. Going from evidence to recommendations. BMJ 2008;336:1049-1051.

14. Present DH, Meltzer SJ, Krumholz MP, Wolke A, Korelitz BI. 6-Mercaptopurine in the management of inflammatory bowel disease: short- and long-term toxicity. Ann Intern Med 1989;111:641-649.

15. Connell WR, Kamm MA, Ritchie JK, Lennard-Jones JE. Bone marrow toxicity caused by azathioprine in inflammatory bowel disease: 27 years of experience. Gut 1993;34:1081-1085.

16. Fraser AG, Orchard TR, Jewell DP. The efficacy of azathioprine for the treatment of inflammatory bowel disease: a 30 year review. Gut 2002;50:485-489.

17. Lee HJ, Yang SK, Kim KJ, et al. The safety and efficacy of azathioprine and 6-mercaptopurine in the treatment of Korean patients with Crohn's disease. Intest Res 2009;7:22-31.
18. Yang SK, Hong M, Baek J, et al. A common missense variant in NUDT15 confers susceptibility to thiopurine-induced leukopenia. Nat Genet 2014;46:1017-1020.

19. Kim JH, Cheon JH, Hong SS, et al. Influences of thiopurine methyltransferase genotype and activity on thiopurineinduced leukopenia in Korean patients with inflammatory bowel disease: a retrospective cohort study. J Clin Gastroenterol 2010;44:e242-e248.

20. Takatsu N, Matsui T, Murakami Y, et al. Adverse reactions to azathioprine cannot be predicted by thiopurine S-methyltransferase genotype in Japanese patients with inflammatory bowel disease. J Gastroenterol Hepatol 2009;24:1258-1264.

21. Ban H, Andoh A, Tanaka A, et al. Analysis of thiopurine Smethyltransferase genotypes in Japanese patients with inflammatory bowel disease. Intern Med 2008;47:1645-1648.

22. Fangbin Z, Xiang G, Minhu C, et al. Should thiopurine methyltransferase genotypes and phenotypes be measured before thiopurine therapy in patients with inflammatory bowel disease? Ther Drug Monit 2012;34:695-701.

23. Gearry RB, Barclay ML. Azathioprine and 6-mercaptopurine pharmacogenetics and metabolite monitoring in inflammatory bowel disease. J Gastroenterol Hepatol 2005;20:11491157.

24. Gisbert JP, Niño P, Rodrigo L, Cara C, Guijarro LG. Thiopurine methyltransferase (TPMT) activity and adverse effects of azathioprine in inflammatory bowel disease: long-term follow-up study of 394 patients. Am J Gastroenterol 2006;101:2769-2776.

25. Schwab M, Schäffeler E, Marx C, et al. Azathioprine therapy and adverse drug reactions in patients with inflammatory bowel disease: impact of thiopurine S-methyltransferase polymorphism. Pharmacogenetics 2002;12:429-436.

26. Winter JW, Gaffney D, Shapiro D, et al. Assessment of thiopurine methyltransferase enzyme activity is superior to genotype in predicting myelosuppression following azathioprine therapy in patients with inflammatory bowel disease. Aliment Pharmacol Ther 2007;25:1069-1077.

27. Colombel JF, Ferrari N, Debuysere H, et al. Genotypic analysis of thiopurine $S$-methyltransferase in patients with Crohn's disease and severe myelosuppression during azathioprine therapy. Gastroenterology 2000;118:1025-1030.

28. Dewit O, Moreels T, Baert F, et al. Limitations of extensive TPMT genotyping in the management of azathioprineinduced myelosuppression in IBD patients. Clin Biochem 2011;44:1062-1066.

29. Booth RA, Ansari MT, Loit E, et al. Assessment of thiopurine Smethyltransferase activity in patients prescribed thiopurines: a systematic review. Ann Intern Med 2011;154:814-823. 
30. Collie-Duguid ES, Pritchard SC, Powrie RH, et al. The frequency and distribution of thiopurine methyltransferase alleles in Caucasian and Asian populations. Pharmacogenetics 1999;9:37-42.

31. Schaeffeler E, Fischer C, Brockmeier D, et al. Comprehensive analysis of thiopurine S-methyltransferase phenotype-genotype correlation in a large population of German-Caucasians and identification of novel TPMT variants. Pharmacogenetics 2004;14:407-417.

32. Sandborn WJ. Rational dosing of azathioprine and 6-mercaptopurine. Gut 2001;48:591-592.

33. Yip JS, Woodward M, Abreu MT, Sparrow MP. How are Azathioprine and 6-mercaptopurine dosed by gastroenterologists? Results of a survey of clinical practice. Inflamm Bowel Dis 2008;14:514-518.

34. Kim JH, Cheon JH, Kim TI, Kim WH. A survey of actual clinical practice patterns in the treatment of inflammatory bowel disease in Korea. Intest Res 2009;7:79-85.

35. Hyun KH, Lee SH, Shin JM, et al. Frequency of bone marrow toxicity by using pattern of azathioprine in inflammatory bowel disease patients. Intest Res 2012;10:244-250.

36. Yu LF, Zhong J, Cheng SD, Tang YH, Miao F. Low-dose azathioprine effectively improves mucosal healing in Chinese patients with small bowel Crohn's disease. J Dig Dis 2014;15:180187.

37. Hibi T, Naganuma M, Kitahora T, Kinjyo F, Shimoyama T. Low-dose azathioprine is effective and safe for maintenance of remission in patients with ulcerative colitis. J Gastroenterol 2003;38:740-746.

38. Park SK, Yang SK, Ye BD, et al. The long-term efficacy of azathioprine in steroid-dependent ulcerative colitis. Scand J Gastroenterol 2013;48:1386-1393.

39. Yang JJ, Landier W, Yang W, et al. Inherited NUDT15 variant is a genetic determinant of mercaptopurine intolerance in children with acute lymphoblastic leukemia. J Clin Oncol 2015;33:1235-1242.

40. Khan KJ, Dubinsky MC, Ford AC, Ullman TA, Talley NJ, Moayyedi P. Efficacy of immunosuppressive therapy for inflammatory bowel disease: a systematic review and metaanalysis. Am J Gastroenterol 2011;106:630-642.

41. Gisbert JP, Linares PM, McNicholl AG, Maté J, Gomollón F. Meta-analysis: the efficacy of azathioprine and mercaptopurine in ulcerative colitis. Aliment Pharmacol Ther 2009;30:126-137.

42. Prefontaine E, Macdonald JK, Sutherland LR. Azathioprine or 6-mercaptopurine for induction of remission in Crohn's disease. Cochrane Database Syst Rev doi: 10.1002/14651858. CD000545.pub3. Published online 16 June 2010.
43. Chande N, Tsoulis DJ, MacDonald JK. Azathioprine or 6-mercaptopurine for induction of remission in Crohn's disease. Cochrane Database Syst Rev doi: 10.1002/14651858.CD000545. pub4. Published online 30 April 2013.

44. Terdiman JP, Gruss CB, Heidelbaugh JJ, Sultan S, Falck-Ytter YT; AGA Institute Clinical Practice and Quality Management Committee. American Gastroenterological Association Institute guideline on the use of thiopurines, methotrexate, and anti-TNF- $\alpha$ biologic drugs for the induction and maintenance of remission in inflammatory Crohn's disease. Gastroenterology 2013;145:1459-1463.

45. D'Haens G, Geboes K, Rutgeerts P. Endoscopic and histologic healing of Crohn's (ileo-) colitis with azathioprine. Gastrointest Endosc 1999;50:667-671.

46. Candy S, Wright J, Gerber M, Adams G, Gerig M, Goodman R. A controlled double blind study of azathioprine in the management of Crohn's disease. Gut 1995;37:674-678.

47. Markowitz J, Grancher K, Kohn N, Lesser M, Daum F. A multicenter trial of 6-mercaptopurine and prednisone in children with newly diagnosed Crohn's disease. Gastroenterology 2000;119:895-902.

48. Dignass A, Lindsay JO, Sturm A, et al. Second European evidence-based consensus on the diagnosis and management of ulcerative colitis part 2: current management. J Crohns Colitis 2012;6:991-1030.

49. Treton X, Bouhnik Y, Mary JY, et al. Azathioprine withdrawal in patients with Crohn's disease maintained on prolonged remission: a high risk of relapse. Clin Gastroenterol Hepatol 2009; 7:80-85.

50. Vilien M, Dahlerup JF, Munck LK, Nørregaard P, Grønbaek K, Fallingborg J. Randomized controlled azathioprine withdrawal after more than two years treatment in Crohn's disease: increased relapse rate the following year. Aliment Pharmacol Ther 2004;19:1147-1152.

51. Kennedy NA, Kalla R, Warner B, et al. Thiopurine withdrawal during sustained clinical remission in inflammatory bowel disease: relapse and recapture rates, with predictive factors in 237 patients. Aliment Pharmacol Ther 2014;40:1313-1323.

52. Lémann M, Mary JY, Colombel JF, et al. A randomized, doubleblind, controlled withdrawal trial in Crohn's disease patients in long-term remission on azathioprine. Gastroenterology 2005;128:1812-1818.

53. French H, Mark Dalzell A, Srinivasan R, El-Matary W. Relapse rate following azathioprine withdrawal in maintaining remission for Crohn's disease: a meta-analysis. Dig Dis Sci 2011;56:1929-1936. 
54. Cassinotti A, Actis GC, Duca P, et al. Maintenance treatment with azathioprine in ulcerative colitis: outcome and predictive factors after drug withdrawal. Am J Gastroenterol 2009;104:2760-2767.

55. Lobel EZ, Korelitz BI, Xuereb MA, Panagopoulos G. A search for the optimal duration of treatment with 6-mercaptopurine for ulcerative colitis. Am J Gastroenterol 2004;99:462-465.

56. Dignass A, Van Assche G, Lindsay JO, et al. The second European evidence-based Consensus on the diagnosis and management of Crohn's disease: current management. J Crohns Colitis 2010;4:28-62.

57. Chaparro M, Ordás I, Cabré E, et al. Safety of thiopurine therapy in inflammatory bowel disease: long-term follow-up study of 3931 patients. Inflamm Bowel Dis 2013;19:1404-1410.

58. Baert F, Noman M, Vermeire S, et al. Influence of immunogenicity on the long-term efficacy of infliximab in Crohn's disease. N Engl J Med 2003;348:601-608.

59. Colombel JF, Sandborn WJ, Reinisch W, et al. Infliximab, azathioprine, or combination therapy for Crohn's disease. N Engl J Med 2010;362:1383-1395.

60. Lémann M, Mary JY, Duclos B, et al. Infliximab plus azathioprine for steroid-dependent Crohn's disease patients: a randomized placebo-controlled trial. Gastroenterology 2006;130:1054-1061.

61. Kopylov U, Al-Taweel T, Yaghoobi M, et al. Adalimumab monotherapy versus combination therapy with immunomodulators in patients with Crohn's disease: a systematic review and meta-analysis. J Crohns Colitis 2014;8:1632-1641.

62. Panaccione R, Ghosh S, Middleton S, et al. Combination therapy with infliximab and azathioprine is superior to monotherapy with either agent in ulcerative colitis. Gastroenterology 2014;146:392-400.

63. Marehbian J, Arrighi HM, Hass S, Tian H, Sandborn WJ. Adverse events associated with common therapy regimens for moderate-to-severe Crohn's disease. Am J Gastroenterol 2009;104:2524-2533.

64. Lichtenstein GR, Feagan BG, Cohen RD, et al. Serious infection and mortality in patients with Crohn's disease: more than 5 years of follow-up in the TREAT registry. Am J Gastroenterol 2012;107:1409-1422.

65. Pariente B, Laharie D. Review article: why, when and how to de-escalate therapy in inflammatory bowel diseases. Aliment Pharmacol Ther 2014;40:338-353.

66. Mason M, Siegel CA. Do inflammatory bowel disease therapies cause cancer? Inflamm Bowel Dis 2013;19:1306-1321.
67. Moran GW, Lim AW, Bailey JL, et al. Review article: dermatological complications of immunosuppressive and anti-TNF therapy in inflammatory bowel disease. Aliment Pharmacol Ther 2013;38:1002-1024.

68. Cozijnsen MA, Escher JC, Griffiths A, Turner D, de Ridder L. Benefits and risks of combining anti-tumor necrosis factor with immunomodulator therapy in pediatric inflammatory bowel disease. Inflamm Bowel Dis 2015;21:951-961.

69. Herrinton LJ, Liu L, Weng X, Lewis JD, Hutfless S, Allison JE Role of thiopurine and anti-TNF therapy in lymphoma in inflammatory bowel disease. Am J Gastroenterol 201 1;106:21462153.

70. Dulai PS, Siegel CA, Peyrin-Biroulet L. Anti-tumor necrosis factor- $\alpha$ monotherapy versus combination therapy with an immunomodulator in IBD. Gastroenterol Clin North Am 2014;43:441-456.

71. Siegel CA, Finlayson SR, Sands BE, Tosteson AN. Adverse events do not outweigh benefits of combination therapy for Crohn's disease in a decision analytic model. Clin Gastroenterol Hepatol 2012;10:46-51.

72. Ananthakrishnan AN, McGinley EL. Infection-related hospitalizations are associated with increased mortality in patients with inflammatory bowel diseases. J Crohns Colitis 2013;7:107-112.

73. Beaugerie L, Brousse N, Bouvier AM, et al. Lymphoproliferative disorders in patients receiving thiopurines for inflammatory bowel disease: a prospective observational cohort study. Lancet 2009;374:1617-1625.

74. Kotlyar DS, Osterman MT, Diamond RH, et al. A systematic review of factors that contribute to hepatosplenic T-cell lymphoma in patients with inflammatory bowel disease. Clin Gastroenterol Hepatol 2011;9:36-41.

75. Kotlyar DS, Lewis JD, Beaugerie L, et al. Risk of lymphoma in patients with inflammatory bowel disease treated with azathioprine and 6-mercaptopurine: a meta-analysis. Clin Gastroenterol Hepatol 2015;13:847-858.

76. Ariyaratnam J, Subramanian V. Association between thiopurine use and nonmelanoma skin cancers in patients with inflammatory bowel disease: a meta-analysis. Am J Gastroenterol 2014;109:163-169.

77. Colombel JF, Loftus EV, Jr., Tremaine WJ, et al. Early postoperative complications are not increased in patients with Crohn's disease treated perioperatively with infliximab or immunosuppressive therapy. Am J Gastroenterol 2004;99:878-883.

78. Myrelid P, Olaison G, Sjödahl R, Nyström PO, Almer S, Andersson $\mathrm{P}$. Thiopurine therapy is associated with postoperative intra-abdominal septic complications in abdominal surgery for Crohn's disease. Dis Colon Rectum 2009;52:1387-1394. 
79. Schaufler C, Lerer T, Campbell B, et al. Preoperative immunosuppression is not associated with increased postoperative complications following colectomy in children with colitis. J Pediatr Gastroenterol Nutr 2012;55:421-424.

80. Ahmed Ali U, Martin ST, Rao AD, Kiran RP. Impact of preoperative immunosuppressive agents on postoperative outcomes in Crohn's disease. Dis Colon Rectum 2014;57:663-674.

81. Selinger CP, Eaden J, Selby W, et al. Inflammatory bowel disease and pregnancy: lack of knowledge is associated with negative views. J Crohns Colitis 2013;7:e206-e213.

82. Nielsen OH, Andreasson B, Bondesen S, Jarnum S. Pregnancy in ulcerative colitis. Scand J Gastroenterol 1983;18:735-742.

83. Reddy D, Murphy SJ, Kane SV, Present DH, Kornbluth AA. Relapses of inflammatory bowel disease during pregnancy: in-hospital management and birth outcomes. Am J Gastroenterol 2008;103:1203-1209.

84. Nørgård B, Hundborg HH, Jacobsen BA, Nielsen GL, Fonager K. Disease activity in pregnant women with Crohn's disease and birth outcomes: a regional Danish cohort study. Am J Gastroenterol 2007;102:1947-1954.

85. Bush MC, Patel S, Lapinski RH, Stone JL. Perinatal outcomes in inflammatory bowel disease. J Matern Fetal Neonatal Med 2004;15:237-241.

86. Fedorkow DM, Persaud D, Nimrod CA. Inflammatory bowel disease: a controlled study of late pregnancy outcome. Am J Obstet Gynecol 1989;160:998-1001.

87. Morales M, Berney T, Jenny A, Morel P, Extermann P. Crohn's disease as a risk factor for the outcome of pregnancy. Hepatogastroenterology 2000;47:1595-1598.

88. Goldstein LH, Dolinsky G, Greenberg R, et al. Pregnancy outcome of women exposed to azathioprine during pregnancy. Birth Defects Res A Clin Mol Teratol 2007;79:696-701.

89. Cleary BJ, Källén B. Early pregnancy azathioprine use and pregnancy outcomes. Birth Defects Res A Clin Mol Teratol 2009;85:647-654.

90. Nørgård B, Pedersen L, Christensen LA, Sørensen HT. Therapeutic drug use in women with Crohn's disease and birth outcomes: a Danish nationwide cohort study. Am J Gastroenterol 2007;102:1406-1413.

91. Casanova MJ, Chaparro M, Domènech E, et al. Safety of thiopurines and anti-TNF- $\alpha$ drugs during pregnancy in patients with inflammatory bowel disease. Am J Gastroenterol 2013;108:433-440.

92. Angelberger S, Reinisch W, Messerschmidt A, et al. Long-term follow-up of babies exposed to azathioprine in utero and via breastfeeding. J Crohns Colitis 2011;5:95-100.
93. Shim L, Eslick GD, Simring AA, Murray H, Weltman MD. The effects of azathioprine on birth outcomes in women with inflammatory bowel disease (IBD). J Crohns Colitis 201 1;5:234238.

94. Coelho J, Beaugerie L, Colombel JF, et al. Pregnancy outcome in patients with inflammatory bowel disease treated with thiopurines: cohort from the CESAME Study. Gut 2011;60:198203.

95. Langagergaard V, Pedersen L, Gislum M, Nørgard B, Sørensen HT. Birth outcome in women treated with azathioprine or mercaptopurine during pregnancy: A Danish nationwide cohort study. Aliment Pharmacol Ther 2007;25:73-81.

96. Jharap B, de Boer NK, Stokkers P, et al. Intrauterine exposure and pharmacology of conventional thiopurine therapy in pregnant patients with inflammatory bowel disease. Gut 2014;63:451-457.

97. Gardiner SJ, Gearry RB, Roberts RL, Zhang M, Barclay ML, Begg EJ. Exposure to thiopurine drugs through breast milk is low based on metabolite concentrations in mother-infant pairs. Br J Clin Pharmacol 2006;62:453-456.

98. Akbari M, Shah S, Velayos FS, Mahadevan U, Cheifetz AS. Systematic review and meta-analysis on the effects of thiopurines on birth outcomes from female and male patients with inflammatory bowel disease. Inflamm Bowel Dis 2013;19:1522.

99. Hutson JR, Matlow JN, Moretti ME, Koren G. The fetal safety of thiopurines for the treatment of inflammatory bowel disease in pregnancy. J Obstet Gynaecol 2013;33:1-8.

100. Van Assche G, Dignass A, Reinisch W, et al. The second European evidence-based Consensus on the diagnosis and management of Crohn's disease: special situations. J Crohns Colitis 2010;4:63-101.

101. van der Woude CJ, Kolacek S, Dotan I, et al. European evidenced-based consensus on reproduction in inflammatory bowel disease. J Crohns Colitis 2010;4:493-510.

102. Mowat C, Cole A, Windsor A, et al. Guidelines for the management of inflammatory bowel disease in adults. Gut 2011;60:571-607.

103. van der Woude CJ, Ardizzone S, Bengtson MB, et al. The second European evidenced-based consensus on reproduction and pregnancy in inflammatory bowel disease. J Crohns Colitis 2015;9:107-124.

104. Sau A, Clarke S, Bass J, Kaiser A, Marinaki A, Nelson-Piercy C. Azathioprine and breastfeeding: is it safe? BJOG 2007;114:498501. 
105. de Boer NK, Jarbandhan SV, de Graaf P, Mulder CJ, van Elburg $\mathrm{RM}$, van Bodegraven AA. Azathioprine use during pregnancy: unexpected intrauterine exposure to metabolites. Am J Gastroenterol 2006;101:1390-1392.

106. de Meij TG, Jharap B, Kneepkens CM, et al. Long-term followup of children exposed intrauterine to maternal thiopurine therapy during pregnancy in females with inflammatory bowel disease. Aliment Pharmacol Ther 2013;38:38-43.

107. Wallace TM, Veldhuyzen van Zanten SJ. Frequency of use and standards of care for the use of azathioprine and 6-mercaptopurine in the treatment of inflammatory bowel disease: a systematic review of the literature and a survey of Canadian gastroenterologists. Can J Gastroenterol 2001;15:21-28.

108. Lewis JD, Abramson O, Pascua M, et al. Timing of myelosuppression during thiopurine therapy for inflammatory bowel disease: implications for monitoring recommendations. Clin Gastroenterol Hepatol 2009; 7:1195-1201.

109. El-Matary W. Letter: thiopurine blood monitoring for patients with inflammatory bowel disease. Aliment Pharmacol Ther 2012;35:742; author reply 743-744.

110. Derijks LJ, Gilissen LP, Hooymans PM, Hommes DW. Review article: thiopurines in inflammatory bowel disease. Aliment Pharmacol Ther 2006;24:715-729.

111. Teml A, Schaeffeler E, Herrlinger KR, Klotz U, Schwab M. Thiopurine treatment in inflammatory bowel disease: clinical pharmacology and implication of pharmacogenetically guided dosing. Clin Pharmacokinet 2007;46:187-208.
112. Cuffari C, Théorêt Y, Latour S, Seidman G. 6-Mercaptopurine metabolism in Crohn's disease: correlation with efficacy and toxicity. Gut 1996;39:401-406.

113. Dubinsky MC, Lamothe S, Yang HY, et al. Pharmacogenomics and metabolite measurement for 6-mercaptopurine therapy in inflammatory bowel disease. Gastroenterology 2000;118:705-713.

114. Palmer SM, Baz MA, Sanders L, et al. Results of a randomized, prospective, multicenter trial of mycophenolate mofetil versus azathioprine in the prevention of acute lung allograft rejection. Transplantation 2001;71:1772-1776.

115. Dubinsky MC, Yang H, Hassard PV, et al. 6-MP metabolite profiles provide a biochemical explanation for 6-MP resistance in patients with inflammatory bowel disease. Gastroenterology 2002;122:904-915.

116. Achkar JP, Stevens T, Easley K, Brzezinski A, Seidner D, Lashner $\mathrm{B}$. Indicators of clinical response to treatment with sixmercaptopurine or azathioprine in patients with inflammatory bowel disease. Inflamm Bowel Dis 2004;10:339-345.

117. Cuffari C, Hunt S, Bayless T. Utilisation of erythrocyte 6-thioguanine metabolite levels to optimise azathioprine therapy in patients with inflammatory bowel disease. Gut 2001;48:642646.

118. Moreau AC, Paul S, Del Tedesco E, et al. Association between 6-thioguanine nucleotides levels and clinical remission in inflammatory disease: a meta-analysis. Inflamm Bowel Dis 2014;20:464-471. 